American Journal of Applied Sciences 7 (1): 44-50, 2010

ISSN 1546-9239

(C) 2010 Science Publications

\title{
The Effect of Methionine and Threonine Supplementations on Immune Responses of Broiler Chickens Challenged with Infectious Bursal Disease
}

\author{
${ }^{1}$ Elham Maroufyan, ${ }^{1}$ Azhar Kasim, ${ }^{2}$ Seyed Reza Hashemi, ${ }^{1}$ Tech Chwen Loh, \\ ${ }^{3}$ Mohd Hair Bejo and ${ }^{4}$ Homa Davoodi \\ ${ }^{1}$ Department of Animal Sciences, University Putra Malaysia, 43400 UPM, \\ Serdang, Selangor, Malaysia \\ ${ }^{2}$ Department of Animal Sciences, \\ Gorgan University of Agricultural Sciences and Natural Resources, Iran \\ ${ }^{3}$ Department of Veterinary Pathology and Microbiology, \\ ${ }^{4}$ Department of Pathology, \\ University Putra Malaysia, 43400 UPM, Serdang, Selangor, Malaysia
}

\begin{abstract}
Problem statement: The aim of this study was conducted to determine the effects of supplementing methionine and threonine higher than the National Research Council (NRC) recommendation in the diets on immune responses of broiler chickens challenged with Infectious Bursal Disease (IBD). Approach: A total of 450 day-old male broiler chicks were assigned to one of the nine dietary treatments. Three levels of methionine (NRC (M1), 2 times NRC (M2) and 3 times NRC (M3)) and 3 levels of threonine (NRC (T1), 2 times NRC (T2) and 3 times NRC (T3)) were fed. On day 28, all birds were challenged with a commercial live-IBDV vaccine. Results: Antibody titer against IBD and ND were influenced by interaction of threonine and methionine. On 7 days after IBD challenge, ND antibody titer of the broilers receiving the highest level of methionine and threonine was significantly higher than that of other treatment groups. Lesion score of the bursa of the broilers receiving control diet was significantly the highest compared with the other treatments. Conclusion/Recommendations: The results obtained on the present study indicated that threonine and methionine requirements of broiler based on recommendation of NRC are not sufficient to meet the requirement of the new commercial poultry and commercial broiler companies under non-hygienic condition.
\end{abstract}

Key words: Infectious bursal disease, methionine, threonine, broiler, immune system

\section{INTRODUCTION}

Infectious Bursal Disease (IBD) is one of the most relevant diseases for worldwide and probably the most important chicken disease that has emerged in the last 30 years. IBD is caused by a virus that is a member of the genus Avibirnavirus of the family Birnaviridae. IBD viral infection suppresses the immune system in young chickens, making birds susceptible to other disease. It's associated with enteric infections and leads to reduce feed conversion and growth rates (Dobos et al., 1979; Becht and Müller, 1991). In poultry production, it is very important to improve immunity so as to prevent infectious diseases. Minimizing immunosuppression and its impact is an important strategy for success in the broiler industry. However, strategies to control immunosuppression are largely based on vaccination programs for broiler breeders and broiler progeny and management to minimize stress during rearing (Fussell, 1998). Utilization of immunostimulants is one solution to improve the immunity of animals and to decrease their susceptibility to infectious diseases (Liu, 1999). There are extremely important interactions, synergisms and antagonisms between nutrition and immunity that markedly affect productivity of poultry. Severe chronic deficiencies of most nutrients impair the immune response and increase the susceptibility to infectious diseases. Severe nutrient deficiencies are particularly

Corresponding Author: Seyed Reza Hashemi, Department of Animal Sciences,

Gorgan University of Agricultural Sciences and Natural Resources, Iran

Tel: 0060196448084; 00989111704427 
deleterious to the immune system when they occur early in life during the development of the primary lymphoid organs and the maturation of immune system (Kirk, 1997). Experiments in chickens and mammalian species have shown that protein or amino acid deficiencies may reduce the circulating antibodies available to challenge organisms. For example, methionine, which is the first limiting amino acid in most commercial feeds and the most likely nutrient to be marginally deficient, has been shown to be important in antibody production to the point that the broiler's methionine requirement for optimum immunity is higher than the requirement for growth or feed conversion. Minimum requirements for a given nutrient for maximum production are fully established (NRC, 1994). On the other hand, the National Research Council (NRC) recommendation are usually based on the needs of healthy birds under ideal management, but birds in commercial systems are normally exposed to different kinds of stresses that it may be necessary for new research to conduct multiple focus and attention to the actual broiler requirements. However, in many cases it is not known whether the requirement values that maximize productivity in healthy, unchallenged birds are optimal for immunocompetence and disease resistance. An understanding of the mechanisms through which nutrition influences the immune system is necessary to appreciate the many complex interactions between diet and infectious diseases. There is some evidence that essential amino acids levels in the feed higher than NRC specifications needed to achieve optimal growth performance, immunocompetence and disease resistance (Kidd et al., 2001; Quentin et al., 2005). Therefore, it may be necessary for new research to conduct multiple focus and attention to the actual broiler requirements. Therefore, the present experiment was conducted to determine the effects supplementing methionine and threonine higher than NRC recommendation in the diets on immune responses of broiler chickens challenged with infectious bursal disease.

\section{MATERIALS AND METHODS}

Birds and housing environment: A total of four hundred fifty day-old male broiler chicks (Cobb 500) were obtained from a local hatchery. The chicks were wing-banded, individually weighed and housed in floor pens with wood shavings as litter material. The pens were in a conventional open-sided house with cyclic temperatures (minimum, $24^{\circ} \mathrm{C}$; maximum, $32^{\circ} \mathrm{C}$ ). The relative humidity was between $80-90 \%$. The area of

each pen was $2 \mathrm{~m}^{2}$. Feed and water were provided ad libitium and lighting was continuous.

Experimental design: Commencing from day one, five replicate pens of 10 chicks each were assigned to one of the nine dietary treatments, giving a total of 45 pens. There were 3 levels of methionine in the form of DLmethionine (NRC (M1), 2 times NRC (M2) and 3 times NRC (M3)) and 3 levels of threonine in the form of Lthreonine (NRC (T1), 2 times NRC (T2) and 3 times NRC (T3)). Birds aged 0-21 days fed diets containing graded concentrations of methionine (NRC, $0.75 \%$ and $1.27 \%$ of diet) and threonine (NRC, $0.82 \%$ and $1.62 \%$ of diet) and diets with similarly graded concentrations of methionine (NRC, 0.49 and $0.88 \%$ of diet) and threonine (NRC, 0.76 and $1.51 \%$ of diet) to birds aged 22-42 days. The basal diets (mash form) were formulated to meet or exceed requirements by the NRC (1994) for broiler chickens (Table 1). No antimicrobial, anticoccidial drugs or feed enzymes were included in the basal diets. The chicks were vaccinated against Newcastle disease (Animal Health, Fort Dodge, Iowa, USA) on day 7 (Intraocular) and on day 21(intranasal).

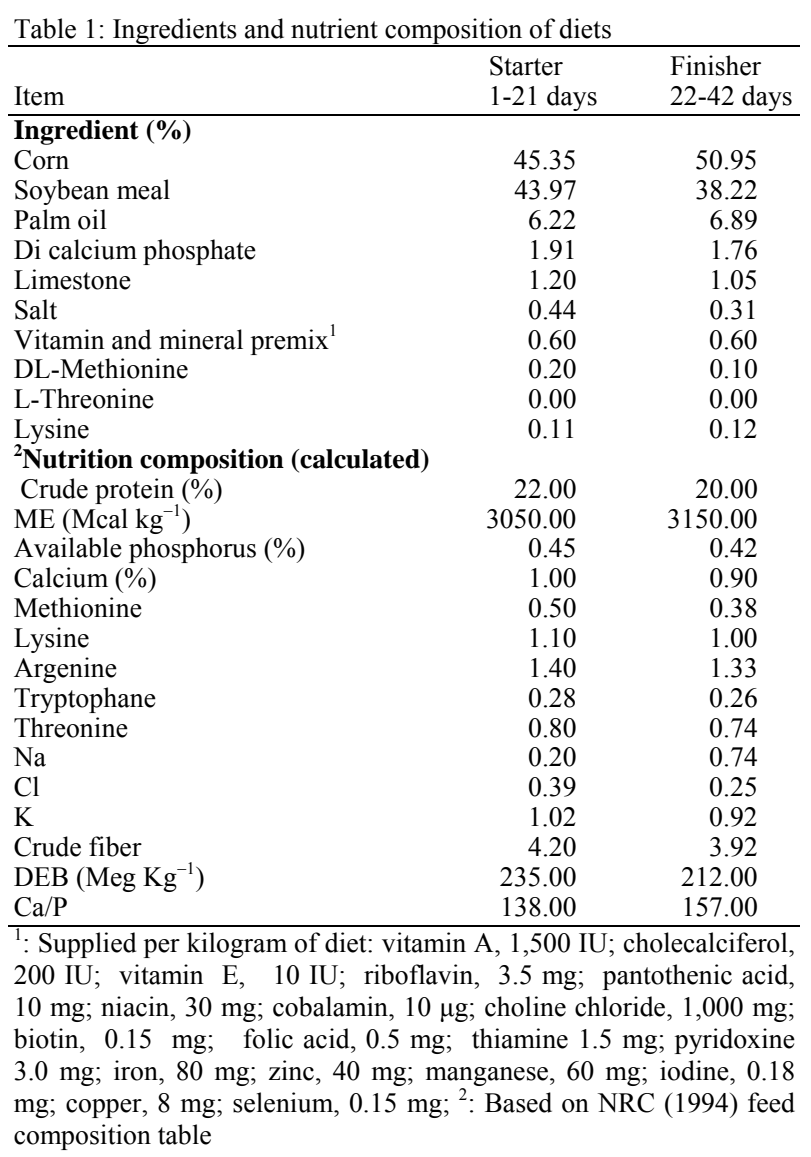


Challenge protocol: On day 28, all birds were challenged by oral route with a commercial live-IBDV vaccine (V877 strain, Malaysian Vaccines and Pharmaceuticals Sdn. Bhd). The strain was characterized as an intermediate virulent classical strain. The content of the 1000 dose of IBD vaccine vial was reconstituted in $100 \mathrm{~mL}$ distilled water and each bird was inoculated with $1 \mathrm{~mL}$ IBD virus into the lumen of the crop by oral gavage, that finally each bird received a dose ten times greater than the standard IBD vaccine.

Serology and immune responses: On 28, 35 and 42 days, ten birds from each group were chosen at random and blood samples were collected from the brachial vein. Serum was separated by centrifugation $(3000 \mathrm{~g}$, $15 \mathrm{~min}$ ) and antibody titre against ND and IBD were performed using commercially available ELISA kits (IDEXX, Labs Inc., Westbrook, Maine, USA) according to manufacturer's instructions. One hundred microliters of serum from each sample were used in the assay. ELISA absorbency was measured at $650 \mathrm{~nm}$ using an ELISA reader (Bio-Tek Instruments Inc. ELX 800; Winooski, VT) by standard procedures.

Histopathological studies and bursal lesion score: Bursal lesion score of broiler chickens, which were collected on days 28 and 42 was determined as per the method of Muskett et al. (1979) on a 0-5 scale (0: no lesion, 1: slight change, 2: scattered or partial bursal damage, 3: $50 \%$ or less follicle damage, 4: $51-75 \%$ follicle damage, $5: 76-100 \%$ bursal damage). Briefly, eight birds from each treatment group were chosen at random and killed and their bursas of Fabricius were removed. Tissues were fixed in 10\% neutral-buffered formalin for 24 hours, before being processed for routine paraffin embedding. Tissues were dehydrated with serial ethanol cycles ( $70 \%$ to absolute), followed by clarification in xylin and then embedded in paraffin. Embedding was carried out with a paraffin embedding station (EG 1160; Leica). Duplicate slides of each block were obtained. Slices of $5 \mu \mathrm{m}$ were produced with a rotation microtome (RM 2155; Leica). Deparaffination was performed with the following protocol: Xylin $4 \mathrm{~min} ; 100,90,70$ and $60 \%$ ethanol for two min each. The slices were then stained with Mayer hematoxylin and eosin and mounted with mounting medium (DPX). Sections were then screened under the light microscope (Leica DM LB2, Leica Microsystems) at low $(\times 5)$ and high $(\times 40)$ magnifications for histopathological study (Hashemi et al., 2008).

Statistical analysis: The data were analyzed by twoway ANOVAS in a completely randomized design in a factorial scheme of $3 \times 3$ (methionine levels $\times$ threonine levels) with the PROC GLM procedure of the statistical analysis system (SAS Institute, 2005). All data presented in this paper are the actual untransformed data except log-transformed data were used for ND and IBD antibody titers when necessary to best approximate the normal distribution. The results were expressed as mean \pm standard error of mean. Statistical significance was considered at $\mathrm{p} \leq 0.05$.

\section{RESULTS}

The IBD antibody titer was significantly higher before and 7 days after challenge in birds fed the highest level of methionine and threonine (Table 2). When methionine $x$ threonine interaction was significant, generally the IBD antibody titers of high level of methionine and threonine were higher than control birds (Table 3). Antibody titer against ND was influenced by a combination of threonine and methionine. On 7 days after IBD challenge, the highest level ND antibody titer was observed in M3T3 group (Table 4).

Table 2: Effect of methionine and threonine on serum antibody titer $\left(\log _{10}\right)$ in broiler chickens challenged with IBD

\begin{tabular}{|c|c|c|c|c|c|c|}
\hline \multirow[b]{2}{*}{ Main effect } & \multicolumn{2}{|c|}{ Pre-challenge } & \multicolumn{2}{|c|}{7 days post challenge } & \multicolumn{2}{|c|}{14 days post challenge } \\
\hline & IBD & ND & IBD & ND & IBD & ND \\
\hline M1 & $1.7 \pm 0.13^{\mathrm{b}}$ & $2.13 \pm 0.08$ & $2.8 \pm 0.11^{\mathrm{b}}$ & $2.85 \pm 0.13$ & $4.0 \pm 0.053$ & $0.11 \pm 0.12$ \\
\hline M2 & $1.6 \pm 0.15^{\mathrm{b}}$ & $2.19 \pm 0.09$ & $3.1 \pm 0.10^{\mathrm{ab}}$ & $3.15 \pm 0.12$ & $4.0 \pm 0.050$ & $3.22 \pm 0.11$ \\
\hline M3 & $2.5 \pm 0.11^{\mathrm{a}}$ & $2.34 \pm 0.87$ & $3.3 \pm 0.11^{\mathrm{a}}$ & $2.93 \pm 0.13$ & $4.0 \pm 0.050$ & $3.01 \pm 0.13$ \\
\hline $\mathrm{T} 1$ & $1.3 \pm 0.13^{\mathrm{c}}$ & $2.15 \pm 0.08$ & $2.9 \pm 0.11^{\mathrm{b}}$ & $2.98 \pm 0.11$ & $3.9 \pm 0.050$ & $2.75 \pm 0.12^{\mathrm{b}}$ \\
\hline $\mathrm{T} 2$ & $2.1 \pm 0.13^{\mathrm{b}}$ & $2.28 \pm 0.08$ & $3.0 \pm 0.10^{\mathrm{b}}$ & $3.02 \pm 0.12$ & $4.0 \pm 0.050$ & $3.23 \pm 0.12^{\mathrm{a}}$ \\
\hline $\mathrm{T} 3$ & $2.5 \pm 0.13^{\mathrm{a}}$ & $2.24 \pm 0.09$ & $3.3 \pm 0.11^{\mathrm{a}}$ & $2.92 \pm 0.14$ & $4.0 \pm 0.050$ & $3.36 \pm 0.12^{\mathrm{a}}$ \\
\hline \multicolumn{7}{|c|}{ ANOVA (p-value) } \\
\hline $\mathrm{M}$ & $* * *$ & NS & $* *$ & NS & NS & NS \\
\hline $\mathrm{T}$ & $* *$ & NS & $*$ & NS & NS & $* *$ \\
\hline $\mathrm{M} \times \mathrm{T}$ & $* * *$ & $* * *$ & $*$ & NS & NS & NS \\
\hline
\end{tabular}


Am. J. Applied Sci., 7 (1): 44-50, 2010

Table 3: Interaction effect (Met $\times$ Thr) on serum IBD antibody titer $\left(\log _{10}\right)$ broiler chickens challenged with IBD

\begin{tabular}{|c|c|c|c|c|c|c|}
\hline \multirow[b]{2}{*}{ Treatments } & \multicolumn{3}{|c|}{ Pre-challenge } & \multicolumn{3}{|c|}{7 days post challenge } \\
\hline & M1 & M2 & M3 & M1 & M2 & M3 \\
\hline T1 & $0.9 \pm 0.2^{\text {by }}$ & $0.3 \pm 0.3^{\text {by }}$ & $2.5 \pm 0.2^{\mathrm{axy}}$ & $2.1 \pm 0.21^{\text {by }}$ & $3.2 \pm 0.18^{\text {axy }}$ & $3.4 \pm 0.20^{\mathrm{a}}$ \\
\hline $\mathrm{T} 2$ & $1.7 \pm 0.2^{\text {by }}$ & $2.4 \pm 0.2^{\mathrm{ax}}$ & $2.4 \pm 0.2^{\text {ay }}$ & $3.0 \pm 0.18^{\mathrm{x}}$ & $2.8 \pm 0.19^{\mathrm{y}}$ & $3.2 \pm 0.19$ \\
\hline $\mathrm{T} 3$ & $2.6 \pm 0.2^{\mathrm{abx}}$ & $2.2 \pm 0.3^{\mathrm{bx}}$ & $2.8 \pm 0.2^{\mathrm{ax}}$ & $3.2 \pm 0.18^{\mathrm{x}}$ & $3.6 \pm 0.19^{x}$ & $3.4 \pm 0.20$ \\
\hline
\end{tabular}

${ }^{\mathrm{x}-\mathrm{z}}$ : Means within a column-subgroup; ${ }^{\mathrm{a}-\mathrm{c}}$ : Means within a row-subgroup with no common letters differ significantly $(\mathrm{p}<0.05)$

Table 4: Interaction effect (Met $\times$ Thr) on serum ND antibody titer $\left(\log _{10}\right)$ broiler chickens challenged with IBD

\begin{tabular}{|c|c|c|c|}
\hline \multirow[b]{2}{*}{ Treatments } & \multicolumn{3}{|c|}{7 days post challenge } \\
\hline & M1 & M2 & M3 \\
\hline T1 & $2.2 \pm 0.2^{\mathrm{xy}}$ & $2.4 \pm 0.1$ & $1.8 \pm 0.1^{z}$ \\
\hline $\mathrm{T} 2$ & $2.3 \pm 0.1^{\mathrm{x}}$ & $2.1 \pm 0.2$ & $2.3 \pm 0.1^{\mathrm{y}}$ \\
\hline T3 & $1.8 \pm 0.1^{\text {by }}$ & $2.1 \pm 0.2^{\mathrm{b}}$ & $2.8 \pm 0.2^{\mathrm{ax}}$ \\
\hline \multicolumn{4}{|c|}{$\begin{array}{l}\text { X-z: Means within a column-subgroup; }{ }^{\text {a-c }}: \text { Means within a row- } \\
\text { subgroup with no common letters differ significantly }(p<0.05)\end{array}$} \\
\hline \multicolumn{4}{|c|}{$\begin{array}{l}\text { Table 5: Effect of methionine and threonine on histopathological } \\
\text { examinations (lesion score) of bursa in broiler chicken pre- } \\
\text { and post challenge }\end{array}$} \\
\hline Main effects & Pre-challenge & $\begin{array}{l}7 \text { days post } \\
\text { challenge }\end{array}$ & $\begin{array}{l}14 \text { days post } \\
\text { challenge }\end{array}$ \\
\hline M1 & $0.53 \pm 0.15$ & $3.6 \pm 0.18$ & $4.5 \pm 0.16$ \\
\hline M2 & $0.60 \pm 0.15$ & $3.6 \pm 0.18$ & $4.4 \pm 0.15$ \\
\hline M3 & $0.26 \pm 0.15$ & $3.2 \pm 0.18$ & $4.2 \pm 0.15$ \\
\hline T1 & $0.60 \pm 0.18$ & $3.7 \pm 0.18$ & $4.3 \pm 0.16$ \\
\hline $\mathrm{T} 2$ & $0.26 \pm 0.18$ & $3.5 \pm 0.18$ & $4.2 \pm 0.15$ \\
\hline T3 & $0.53 \pm 0.18$ & $3.2 \pm 0.18$ & $4.4 \pm 0.15$ \\
\hline \multicolumn{4}{|c|}{ ANOVA (p-value) } \\
\hline M & NS & NS & NS \\
\hline $\mathrm{T}$ & NS & NS & NS \\
\hline $\mathrm{M} \times \mathrm{T}$ & NS & $*$ & NS \\
\hline
\end{tabular}

Table 6: Interaction effect (Met $\times$ Thr) on histopathological examinations (lesion score) of bursa on $7 \mathrm{~d}$ post challenge in broiler chicken

\begin{tabular}{|c|c|c|c|}
\hline \multirow[b]{2}{*}{ Treatment } & \multicolumn{3}{|c|}{ Lesion score } \\
\hline & M1 & M2 & M3 \\
\hline $\mathrm{T} 1$ & $4.5 \pm 0.3^{\text {ax }}$ & $3.4 \pm 0.3^{b}$ & $3.4 \pm 0.3^{b}$ \\
\hline T2 & $3.2 \pm 0.3^{y}$ & $3.5 \pm 0.3$ & $3.3 \pm 0.3$ \\
\hline T3 & $3.3 \pm 0.3^{y}$ & $3.3 \pm 0.3$ & $3.0 \pm 0.3$ \\
\hline
\end{tabular}

Effects of methionine and threonine supplementation on lesion score of bursa of Fabricius in IBD challenged birds are shown in Table 5. Methionine and threonine had no significant effect on lesion scores of the bursa throughout the duration of study. Significant interaction in lesion scores of the bursa of the broilers was observed following seven days of IBD challenge (Table 6). Lesion score of the bursa of the broilers receiving M1T1 diet was significantly higher than that of other treatment groups.

\section{DISCUSSION}

The control of immunosuppressive diseases is of prime importance for the nascent poultry industry in developing countries. In this regard, improve of feed formulation and enhancement of genetic resistance to economically important diseases should be considered (Bumstead et al., 1991). The resistance against infectious challenges requires an intense response orchestrated by the immune system. From the nutritional standpoint, feed substrates (amino acids, energy and enzymes) are needed to activate such a response (Rubin et al., 2007). Minimum requirements for a given nutrient for maximum production are fully established (NRC, 1994). Typical poultry feeds are furnished by corn and soybean meal may contain less than the desired quantity of methionine and threonine. The low concentration of methionine and threonine high-protein corn-soybean diets has lead to wide use of synthetic methionine and threonine supplementation in poultry feed. Several publications are available on the relation between performance traits and immunological responses. A negative correlation was found between body weight and antibody response in broilers (Kreukniet et al., 1996; Koenen et al., 2002). This correlation was also demonstrated in layer chickens (Gross and Siegel, 1980). Tsiagbe et al., (1987) suggested that the requirement for methionine for maximum antibody titers was greater than that for growth. Infections lead to several changes in amino acid plasma levels. Such alterations are ascribed to a sharp consumption of sulfur amino acids during the infectious challenge, imputable to the metabolic relationships these amino acids maintain with each other (Jeevanandam et al., 1990; Paaw and Davis, 1990). From the nutritional standpoint, amino acids are needed for clonal proliferation of lymphocytes, establishment of germinative centers in the bursa of Fabricius to refine immunoglobulin affinity, recruitment of new bone marrow monocytes and heterocytes and synthesis of effector molecules (immunoglobulins, nitric oxide, lysozyme, complement) and communication molecules (cytokines and eicosanoids, for instance). Methionine plays an important role in humoral and cellular immune 
responses (Swain and Johri, 2000; Shini et al., 2005). It has been suggested that such effect is exerted by intracellular glutathione and cysteine levels (Rubin et al., 2007). One of the mechanisms proposed to explain methionine interference in the immune system is based on the proliferation of immune cells, which are sensitive to intracellular variations in glutathione and cysteine levels, compounds which also participate in the metabolism of methionine (Shini et al., 2005). Glutathione is, quantitatively speaking, the most abundant intracellular antioxidant compound, playing a variety of important roles and being vitally important for the protection against the emergence of oxidative stress that follows inflammatory processes (Le Floc'h et al., 2004). Additionally, there is evidence that threonine modulates immune function in livestock ( $\mathrm{Li}$ et al., 2007) and immune system is sensitive to dietary threonine intake (Li et al., 1999). It has been reported that threonine is a major component of intestinal mucin and plasma $\gamma$-globulin in animals (Kim et al., 2007). Indeed, serum antibody titres increased with increasing dietary intake of threonine in chickens infected with the Newcastle disease virus (Bhargava et al., 1971). Also, dietary supplementation with threonine increased serum levels of IgG in sows (Cuaron et al., 1984). Further, increasing dietary threonine intake increased antibody production, serum IgG levels and jejunal mucosal concentrations of IgG and IgA (Wang et al., 2006). Furthermore, It should be notified that dietary methionine can influence the metabolism of other amino acids (Moritoki and Yoshida,1970; Sanchez et al., 1972) due to the potential effect of dietary methionine on the availability of threonine for host immunity, dietary excessive methionine being capable of depress plasma threonine levels (Moritoki and Yoshida,1970) and stimulating the activity of threonine dehydratase (Sanchez et al., 1972; Sanchez and Swendseid, 1969) a key enzyme in the pathway of serine and threonine catabolism and therefore ability of threonine to increase survival of the host depend on adequate essential amino acid including methionine. This is may that added threonine to methionine supplementation decrease dehydratase activity, which results in a increase of plasma threonine levels and a consequent in more antibody titer production. These observations indicated a synergistic effect of methionine and threonine on the immune response of broiler chicken at concentration higher than the recommendation of NRC (1994).

Under our experimental conditions moderate to extensive histopathological lesions were seen in chicks challenged with IBD. Significant interaction in lesion scores of the bursa of the broilers was observed following seven days after IBD challenge. The severity of histopathological lesions score increased in control group. A decreasing trend of lesion scores with a corresponding increase in dietary methionine and threonine concentration were observed. Bursa of Fabricius is responsible for the development of humoral immunity. The bursal lesions were characterized by lymphoid depletion and edema in the follicles, fibroplasias in the interfollicular connective tissues and proliferation of the reticular epithelial cells (Park et al., 2009). A possible explanation of these results might be that dietary methionine and threonine may have interfered with apoptotic or necrotic process of bursal lymphocytes during infection of IBDV because the use of IBD vaccine can cause a varying degree of bursal lymphocytolysis (Amakye-Anim et al., 2000). Through protein synthesis and cellular signaling mechanisms, addition of threonine to the culture medium prevented apoptosis, stimulated cell growth and promoted antibody production in lymphocytes (Duval et al., 1991).

\section{CONCLUSION}

In conclusion, the results obtained on the present study indicated that threonine and methionine requirements of broiler based on recommendation of the National Research Council (NRC, 1994) are not sufficient to meet the requirement of the new commercial poultry and commercial broiler companies under non-hygienic condition and may have reduced profitability under condition of disease if their broilers are fed on the diets formulated according to the NRC.

\section{ACKNOWLEDGEMENT}

The researcher would like to express their gratitude to Mr. Mazlan Hamzah and Ponnusamy Muniandy the staff of Animal Science Department of Agriculture Faculty, University of Putra Malaysia for their technical assistance during the experimental period.

\section{REFERENCES}

Amakye-Anim, J., T.L. Lin, P.Y. Hester, D. Thiagarajan and B.A. Watkins et al., 2000. Ascorbic acid supplementation improved antibody response to infectious bursal disease vaccination in chickens. Poult. Sci., 79: 680-688.

Becht, H. and H. Müller, 1991. Infectious bursal disease $\mathrm{B}$ cell dependent immunodeficiency syndrome in chickens. Behring Inst. Mitt., 89: 217-225. PMID: 1656933 
Bhargava, K.K., R.P. Hanson and M.L. Sunde., 1971. Effects of threonine on growth and antibody production in chickens infected with Newcastle disease virus. Poult. Sci., 50: 710-713. PMID: 5569753

Bumstead, N., B.J. Millard, B.A. Barrow and J.K.A. Cook, 1991. The Genetic Basis of Disease Resistance in Chickens. In: Breeding for Disease Resistance in Farm Animals, Owan, J.B. and R.P.E. Axford (Eds.). CAB Int., Wallingford, England, ISBN: 0851993257, pp: 10-23.

Cuaron, J.A., R.P. Chapple and R.A. Easter, 1984. Effect of lysine and threonine supplementation of sorghum gestation diets on nitrogen balance and plasma constituents in first-litter gilts. J. Anim. Sci., 58: 631-637.

Dobos, P., B.J. Hill, R. Hallett, D.T. Kells, H. Becht and D. Teninges, 1979. Biophysical and biochemical characterization of five animal viruses with bisegmented double-stranded RNA genomes. J. Virol., 32: 593-605. PMID: 228080

Duval, D., C. Demangel, K. Munierjolain, S. Miossec and I. Geahel, 1991. Factors controlling cell proliferation and antibody production in mouse hybridoma cells. Influence of the amino acid supply. Biotechnol. Bioeng., 38: 561-570. DOI: 10.1002/bit.260380602

Fussell, L.W., 1998. Poultry industry strategies for control of immunosuppressive diseases. Poult. Sci., 77: 1193-1196.

Gross, W.B. and P.B. Siegel, 1980. Effects of early environmental stress on chicken body weight, antibody response to $\mathrm{RBC}$ antigens, feed efficiency and response to fasting. Avian Dis. 24: 569.

Hashemi, S.R., I. Zulkifli, M. Hair Bejo, A. Farida and M.N. Somchit, 2008. Acute toxicity study and phytochemical screening of selected herbal aqueous extract in broiler chickens. Int. J. Pharmacol., 4: 352-360.

Jeevanandam, M., D.H. Young, L. Ramais and W.R. Schiller, 1990. Effect of major trauma on plasma free amino acid concentrations in geriatric patients. Am. J. Clin. Nutr., 51: 1040-1050.

Kidd, M.T., P.D. Gerard, J. Heger, B.J. Kerr and D.E. Rowe et al., 2001. Threonine and crude protein responses in broiler chicks. Anim. Feed Sci. Technol., 94: 57-64. DOI: 10.1016/S03778401(01)00301-7

Kim, S.W., R.D. Mateo, Y.L. Yin and G. Wu, 2007. Functional amino acids and fatty acids for enhancing production performance of sows and piglets. Asian-Aust. J. Anim. Sci., 20: 295-306.
Kirk, C.K., 1997. Interaction between Nutrition and Infections Disease Infectious Disease. Diseases of Poultry. 10th Edn., Mosby-Wolfe, pp: 73-74.

Koenen, M.E., A.G. Boonstra-Blom and S.H.M. Jeurissen, 2002. Immunological differences between layer and broiler-type chickens. Vet. Immunol. Immunopathol., 89: 47-56. PMID: 12208050

Kreukniet, M.B., S.H. Jeurissen, M.G. Nieuwland, N. Gianotten and P. Joling et al., 1996. The B cell compartment of two chicken lines divergently selected for antibody production: Differences in structure and function. Vet. Immunol. Immunopathol., 51: 157-171. DOI: 10.1016/01652427(95)05505-3

Le Floc'h, N., D. Melchior and C. Obled, 2004. Modification of protein and amino acid metabolism during inflammation and immune system activation. Livestock Prod. Sci., 87: 37-45. DOI:10.1016/J.LIVPRODSCI.2003.09.005

Li, D.F., C.T. Xiao, S.Y. Qiao, J.H. Zhang and E.W. Johnson et al., 1999. Effects of dietary threonine on performance, plasma parameters and immune function of growing pigs. Anim. Feed Sci. Technol., 78: 179-188. DOI: 10.1016/S03778401(99)00005-X

Li, P.Y., Yin, D. Li, S.W. Kim and G. Wu, 2007. Amino acids and immune function. Br. J. Nutr., 98: 237-252. DOI: 10.1017/S000711450769936X

Liu, X.Y., 1999. Stress and Immunity. In: Poultry Immunology, Yin, T.B. (Ed.). China Agriculture Press, Beijing, China, pp: 230-252.

Moritoki, K. and A. Yoshida, 1970. Effect of methionine supplementation to a low casein diet on plasma level of threonine and other amino acids of rats. J. Jap. Soc. Food Nutr., 23: 351-355.

Muskett, J.C., I.G. Hopkins, K.P. Edwards and D.H. Thornton, 1979. Comparison of two infectious bursal disease vaccine strains: Efficacy and potential hazards in susceptible and maternally immune birds. Vet. Rec., 104: 332-334. PMID: 224563

National Research Council, 1994. Nutrient Requirement of Poultry. 9th Edn., National Academy Press, Washington DC., ISBN: 13: 9780-309-04892-7, pp: 176.

Paaw, J.D. and A.T. Davis, 1990. Taurine concentrations in serum of critically injured patients and age and sex-matched healthy control subjects. Am. J. Clin. Nutr., 49: 814-822. 
Park, J.H., H.W. Sung, B.I. Yoon and H.M. Kwon, 2009. Protection of chicken against very virulent IBDV provided by in OVO priming with DNA vaccine and boosting with killed vaccine and the adjuvant effects of plasmid-encoded chicken interleukin-2 and interferon- $\gamma$. J. Vet. Sci., 10: 131-139. PMID: 19461208

Quentin, M., I. Bouvarel and M. Picard, 2005. Effects of starter diet, light intensity and essential amino acids level on growth and carcass composition of broilers. J. Applied Poultry Res., 14: 69-76.

Rubin, L.L., A.L.M. Ribeiro, C.W. Canal, I.C. Silva and L. Trevizan et al., 2007. Influence of sulfur amino acid levels in diets of broiler chickens submitted to immune stress. Brazilian J. Poultry Sci., 9: 305-311. DOI: 10.1590/S1516635X2007000100008

Sanchez, A. and M.E. Swendseid, 1969. Amino acid levels and enzyme activity in tissues of rats forcefed diets differing methionine content. J. Nutr., 99: 145-151.

Sanchez, A., M.E. Swendseid, A.J. Clark and C. Umezawa, 1972. Amino acid pools and hepatic enzyme activities in rats fed a meal of high or low methionine content. Am. J. Clin. Nutr., 25: 550-554. PMID: 4402418
Shini, S., X. Li and W.L. Bryden, 2005. Methionine requirement and cell-mediated immunity in chicks. Asia Pac. J. Clin. Nutr. 14: (Suppl) S1-123.

Swain, B.K. and T.S. Johri, 2000. Effect of supplemental methionine, choline and their combinations on the performance and immune response of broilers. Br. Poultry Sci., 41: 83-88. DOI: $0.1080 / 0007166008645$

Tsiagbe, V.K., M.E. Cook, A.E. Harper and M.L. Sunde, 1987. Enhanced immune responses in broiler chick fed methionine supplemented diets. Poult. Sci., 66: 1147-1154. PMID: 3671290

Wang, X., S.Y. Qiao, M. Liu and Y.X. Ma, 2006. Effects of graded levels of true ileal digestible threonine on performance, serum parameters and immune function of 10-25 kg pigs. Anim. Feed Sci. Tech., 129: 264-278. DOI: 10.1016/J.ANIFEEDSCI.2006.01.003 